\title{
Three-phase To Two-phase Matrix Converter with Reduced Switches
}

\author{
M.Rahideh ${ }^{1}$ and A. Dastfan ${ }^{2}$ H.Toossian Shandiz ${ }^{3}$ \\ Faculty of Electrical and Robotic Engineering \\ Shahrood University of Technology \\ Shahrood - (Iran) \\ E-mail: ${ }^{1}$ rahideh.mostafa@,ieee.org ${ }^{2} \underline{\text { Dastfan@,ieee.org }{ }^{3} \text { htshandiz@,shahroodut.ac.ir }}$
}

\begin{abstract}
AC-AC Statistic Matrix converter, also called frequency converters, is the most widely-used and first power electronics systems. These converters are conventionally designed and produced with an AC-DC-AC structure (i.e. a middle DC circuit is used). The used filter in the middle circuit causes system loss and increases the circuit volume. On the other hand, because of the short lifetime of electrolyte capacitors used in the middle DC circuit, reliability decreases. The direct ACAC converter does not have such weaknesses, but the bidirectional switches have not been developed enough and because of commutation problems, these converters are not suitable replacements for the AC-DC-AC converters. To produce two phase voltage, Scott transformers are mostly used for industrial purposes. But the cost and the core loss of Scott transformers are much higher than the matrix converters. In this paper, a two-phase matrix converter is introduced, in which he number of switches are reduced as much as possible in order to decrease the switching losses and to eliminate the commutation problem in line side. Simulation results are presented showing the proposed circuit and it's control working good enough.
\end{abstract}

Key words-Matrix converter, SVM, Reduced Switches

\section{INTRODUCTION}

Matrix converter is a device which converts the AC energy to AC directly. Basically, a three-phase to three-phase matrix converter consists of 9 bidirectional switches, which needs commutation to minimize the losses and to produce the desired output with high quality input and output waveforms, as shown in Fig.1. Matrix converter was first introduced in 1980's by Alesina and Ventarini [1]. Because of several advantages, e.g. power capability in two directions and high quality input and output waveforms, the matrix converters have recently received considerable attention. On the other hand, it can be produced in compact circuits and moreover in smaller sizes since there is no energy saving element like capacitors in DC bus of this converter.

Due to some problems such as: complex commutation and complicated over-voltage protection circuits, the use of matrix converters has been limited in industry. For example, the applications of matrix converters are: induction motor driver, switching power supply, applications in aircraft industry, voltage regulator, Unified Power Flow Controller (UPFC), middle converter in electrical networks with different frequencies. A great number of studies have been



Fig.1 Main circuit of conventional matrix converter.

conducted on practical usages of matrix converters in industry. The studies were in the fields

of safe commutation of matrix converters and the structure of bidirectional switches in them[2] or control of matrix converters using PWM (pulse width modulation)[3],[4]. However, the matrix converter is not widely used in industry. The main problem is the commutation issues of this converter since there should not be any short-circuit of the input circuit and open-circuits in the load side. To solve these problems, some alternatives have been presented in the related literature, but generally these techniques introduce a multistage commutation of a general protection circuit which increases the converter complexity itself.

Later, to reduce the switches of direct matrix converter and to simplify the strategy of commutation in protection circuit against over-voltage, new generations of matrix converters named indirect matrix converters (IMC) were introduced. The IMC topology was first proposed by P.D.Zingas in 1985 [5]. But until 2001 this converter was not known as a matrix converter. By considering the topology of the conventional matrix converter $(\mathrm{CMC})$, the topology of indirect matrix converter (IMC) has recently received considerable attention and has been developed extensively, which it circuit is shown in Fig. 2 .

In reference [6], it is completely explained how 18 switches are reduced to 15 switches and then 15 switches to 12 , and 
finally 12 to 9 switches. The nine-switch converter has 8 switches less than eighteen-switch converter in the line side and in the load side they are same with respect to the number

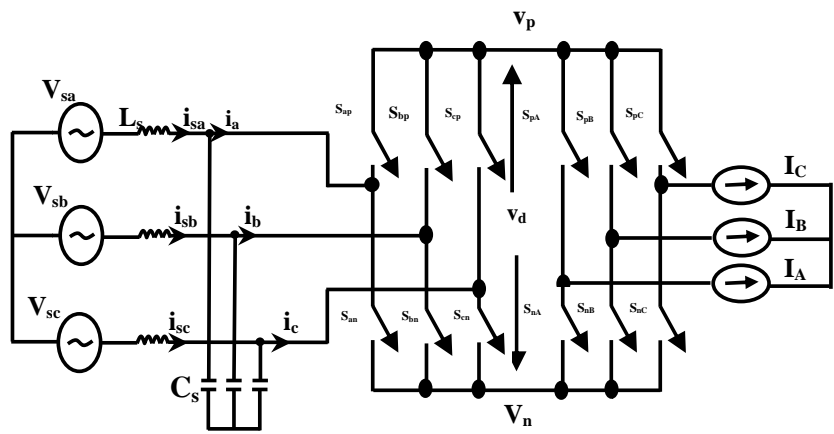

Fig. 2 Indirect matrix convertors topology

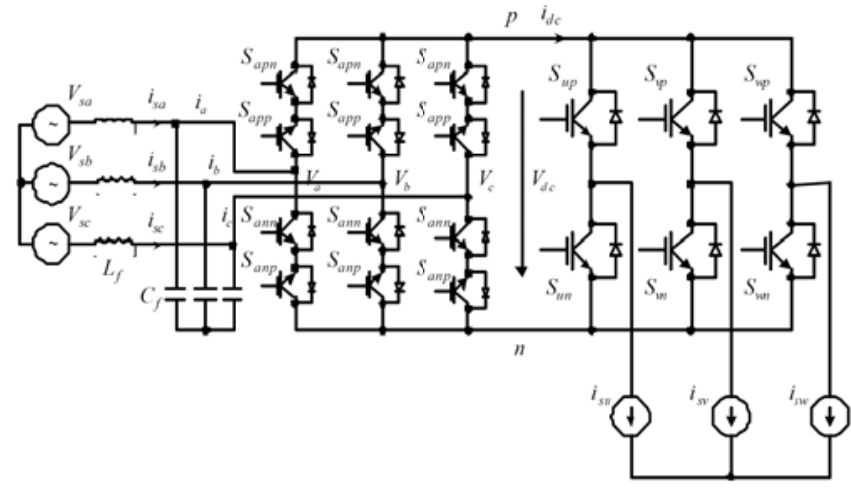

a) 18-switch topology



b) 9-switch topology

Fig. 3 Reduction of switch number to 9 or 18[6]

of switches. It results in a dramatic reduction of switching loss in the line side (Fig. 3). Bidirectional power transmission is the advantage of eighteen-switch converter in comparison with nine-switch converter. In this paper, a one-way supply is the subject matter.

So at the line side of the circuit, three switches (nine-switch model) are used. In addition, to solve the over-voltage problem in DC link, a simple circuit is proposed in reference [6] (a diode with a capacitor) (Fig. 3 (b)). A switching technique is proposed to produce two- phase voltages with 90 phase angle from a DC voltage link produced in ref. [3]. In the load side, one leg is assumed as ground for two other legs as it is shown in Fig. 4.

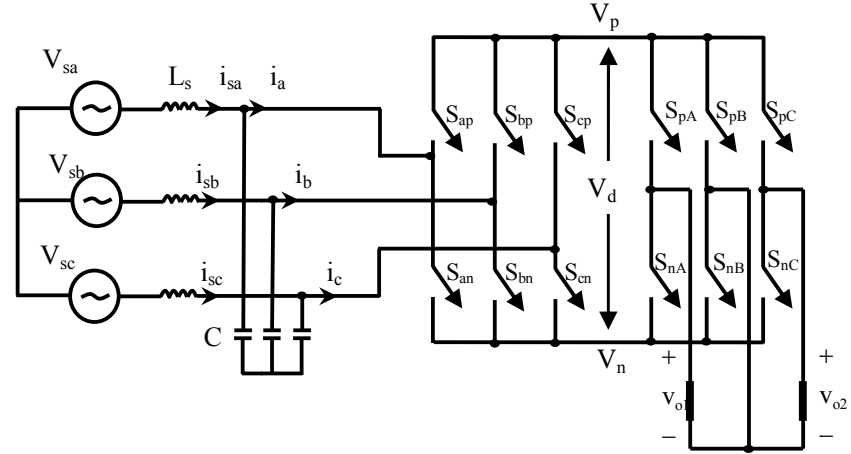

Fig.4 Indirect matrix converter topologies in the occurrence of $\mathrm{C}$ phase with supply neutral

\section{THREE-PHASE TO TWO-PHASE MATRIX CONVERTER STRUCTURS}

The structures of three-phase to two-phase matrix converter two different has been proposed in literatures named: convention matrix converter (CMC) and indirect matrix converter (IMC) in the following section these methods has been detailed.

\section{A. Convention matrix converter(CMC)}

Three-phase to two-phase direct matrix converter can be in two forms: two-leg or three-leg structures [7], as shown in Fig. 5. Since, in two-leg form input and output ground are same; the amplitude of output voltage cannot be more than half the input voltage amplitude. But in three-leg form input ground is separate from output one. The Ratio of output voltage amplitude to input voltage increases $\sqrt{3} / 2$. It is performed by injection of third harmonic to the input voltage. To produce pulse in this model, two techniques has be used including Ventarini and Space Vector Modulation (SVM).

In Ventarini method in order to satisfy the two basic conditions of matrix converter (i.e. no short circuit at input phase terminals, and also no open circuit at output phase terminals) two switches are used to link input phase terminals to output phase ones through bi-directional switches. As turning the switches on and off is doing instaneously in the simulation, we can ignore the time it lasts. To satisfy the mentioned conditions, we use the four-step commutation strategy. It requires the direction of output current of each phase, the sign of output phase current, should be recognized at any instance of time [8]. The generated pulses for $\mathrm{S}_{\mathrm{aA}}$ and $\mathrm{S}_{\mathrm{bB}}$ switches are presented in conclusion.

\section{B. Indirect matrix converter}

Indirect matrix converter is as shown in Fig. 4. To produce the pulse in this converter, the SVM approach is employed. Considering the conventional matrix converter topology in Fig.1, the switching function of a switch, $\mathrm{S} \mathrm{jk}$ is defined as ' 0 ' when open and ' 1 ' when closed and the output voltage of this converter is directly obtained in (1). Here $\mathrm{j}\{\mathrm{a}, \mathrm{b}, \mathrm{c}\}$ and $\mathrm{k}\{\mathrm{A}, \mathrm{B}, \mathrm{C}\}$. 
$\left[V_{k}(t)\right]=\left[S_{j k}\right]\left[V_{j}(t)\right]$

$\left[\begin{array}{c}V_{A}(t) \\ V_{B}(t) \\ V_{C}(t)\end{array}\right]=\left[\begin{array}{lll}S_{a A} & S_{b A} & S_{c A} \\ S_{a B} & S_{b B} & S_{c B} \\ S_{a C} & S_{b C} & S_{c C}\end{array}\right]\left[\begin{array}{c}V_{a}(t) \\ V_{b}(t) \\ V_{c}(t)\end{array}\right]$

$$
\left[\begin{array}{l}
V_{a}(t) \\
V_{b}(t) \\
V_{c}(t)
\end{array}\right]=\left[\begin{array}{c}
V_{m} \cos \left(\omega_{i} t\right) \\
V_{m} \cos \left(\omega_{i} t-\frac{2 \pi}{3}\right) \\
V_{m} \cos \left(\omega_{i} t+\frac{2 \pi}{3}\right)
\end{array}\right]
$$

The Eq. (2) can be converted to two following equations. Two conversion matrixes are produced, one for rectifier and other for inverter.

$\left[\begin{array}{l}V_{A}(t) \\ V_{B}(t) \\ V_{C}(t)\end{array}\right]=\left[\begin{array}{ll}S_{p A} & S_{n A} \\ S_{p B} & S_{n B} \\ S_{p C} & S_{a A}\end{array}\right]\left[\begin{array}{l}V_{p}(t) \\ V_{n}(t)\end{array}\right]$
$\left[\begin{array}{l}V_{p}(t) \\ V_{n}(t)\end{array}\right]=\left[\begin{array}{lll}S_{a p} & S_{b p} & S_{c p} \\ S_{a n} & S_{b n} & S_{c n}\end{array}\right]\left[\begin{array}{l}V_{a}(t) \\ V_{b}(t) \\ V_{c}(t)\end{array}\right]$

C. The rectifier section

To produce a dc-link voltage in the rectifier, the nine-switch technique proposed in ref. [6] was used. The method is completely explained in ref. [6].

\section{The inverter section}

It is used to produce two-phase voltage by the means of threeleg model. In this model, a leg is used as the ground for the other two legs.

$$
\begin{aligned}
& V_{\text {out } 1}(t)=V_{A}(t)-V_{C}(t)=V_{o} \cos \left(\omega_{o} t\right) \\
& V_{\text {out } 2}(t)=V_{B}(t)-V_{C}(t)=V_{o} \cos \left(\omega_{o} t+\frac{\pi}{2}\right)
\end{aligned}
$$

Each switch can be in two positions, ON and OFF. Considering three leg inverter, $2^{3}$ combinations can be achieved.

It is necessary for switches positioned in the same leg, not to be open or close simultaneously. So in order to fulfill the above-called criterion, it would be enough just to produce three pulses for the upper side switches and use the NOT pulses of the upper side pulses for the lower side switches. The eight possible combinations, previously mentioned, are illustrated in table I and Fig.6

Of the eight above-mentioned combinations, eight space vectors are produced. Among these eight vectors, two of them are zero-vectors and six are active vector (non-zero vectors).
TABLE I

SWITCH STATES IN EACH INTERVAL

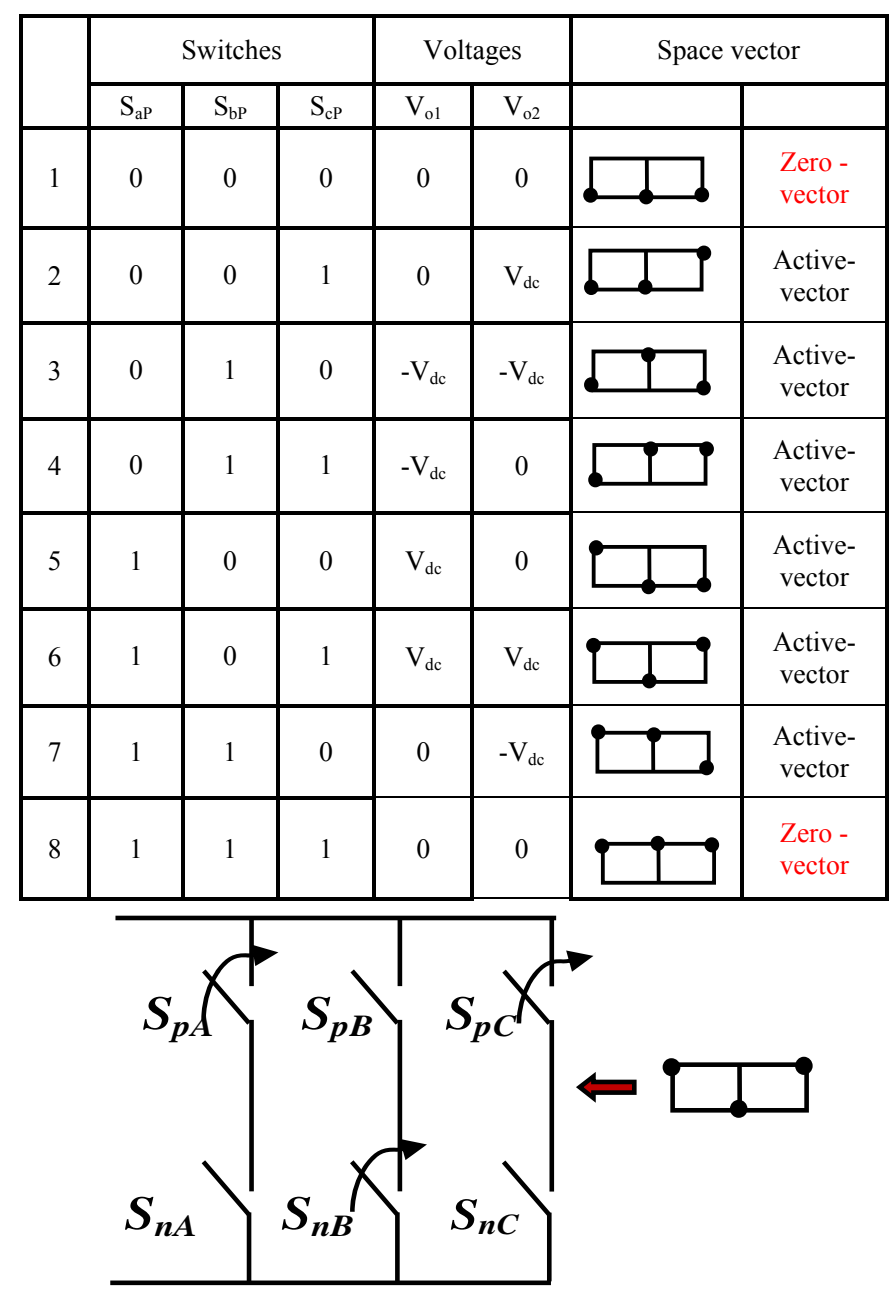

Fig. 6 switching position symbol

In order to produce two-phase voltage, the length of the reference vector must be a constant amount. Of the six active vectors previously mentioned, two of them have different lengths in contrast to the four others, so we omit them and use the remaining four active vectors and two zero-vectors to produce two-phase voltage. Four active vectors have divided the complex plane into four same sections, as shown in Fig. 7. Let's explain a vector located in sector 1 as shown in Fig. 8. This sector is composed of two active vectors which act as two orthogonal axis, and it also includes two zero vectors. The reference vector cycles through this zone with constant length in the range of angle 0 to $\pi / 2$. For each arbitrary angle of the reference vector, the reference vector length-share on vector (100) is $\mathrm{d} 1$ and its length-share on vector (001) is labeled $\mathrm{d} 2$, while $\mathrm{d} 0$ is the reference vector length-share on zero vectors.

In an arbitrary $\mathrm{T}_{\mathrm{s}}$ switching time:

$\mathrm{T}_{1}=\mathrm{d}_{1} \times \cos \theta$

$\mathrm{T}_{2}=\mathrm{d}_{2} \times \cos \theta$

$\mathrm{T}_{0}=\mathrm{T}_{\mathrm{s}}-\mathrm{T}_{1}-\mathrm{T}_{2}$ 
Where $T_{1}$ is the reference vector time-share on vector (100), $\mathrm{T}_{2}$ is the reference vector time-share on vector $(001)$ and $\mathrm{T}_{0}$ the reference vector time-share on vector zero.

It is of great necessity that we design a filter for line section. The designed filter is illustrated.

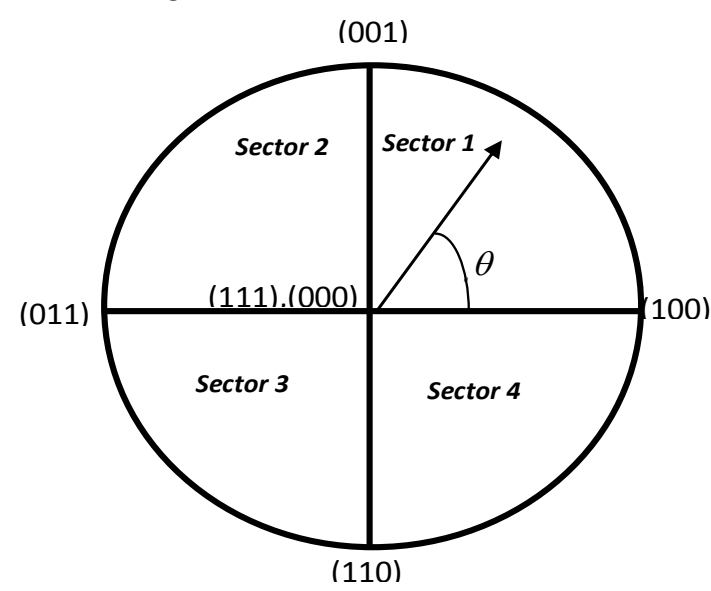

Fig.7. Four active vectors



Fig.8. sector 1

\section{COMMUTATION PROCESS}

Fig. 9 illustrates switches pulses in four-step commutation with output current Io1. Fig. 1 illustrates $\mathrm{S}_{\mathrm{cA}}$ combining of two switches $\mathrm{S}_{\mathrm{cA}(\mathrm{nc})}$ and $\mathrm{S}_{\mathrm{cA}(\mathrm{c})}$ for transferring the negative current and positive current respectively. The switch $\mathrm{S}_{\mathrm{cA} \text { (nc) }}$ is turned off sooner, and the switch $\mathrm{S}_{\mathrm{aA}(\mathrm{c})}$ will not be turned off till $\mathrm{S}_{\mathrm{bB}}$ turned on. After turning $\mathrm{SbA}(\mathrm{c})$ on, $\mathrm{S}_{\mathrm{aA}(\mathrm{c})}$ will be turned off and $S_{b A(n c)}$ will be turned on (see Fig. 10). This time difference is just the same as the time of turning a switch on and off, so that turning two switches off is guaranteed. Under these circumstances the output phase terminals never become open circuit and the input phase terminals are never short circuit. In Fig.11, when the output current Io1 is negative, the order of turning the switches on and off is converted with respect to the pervious case, i.e. $\mathrm{S}_{\mathrm{aA}(\mathrm{c})}$ is the one which turned off first.
: Switch SaA(c) pulse

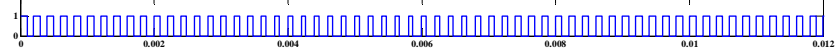
Switch SbA(nc) pulse

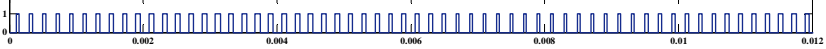
Switch SbA(c) pulse

作

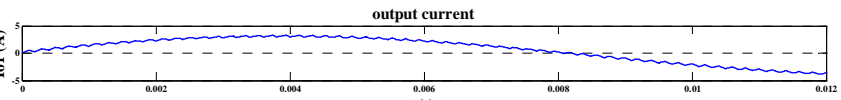

Fig.9 Switches pulses in four-step commutation with output current $\mathrm{I}_{\mathrm{o}}$

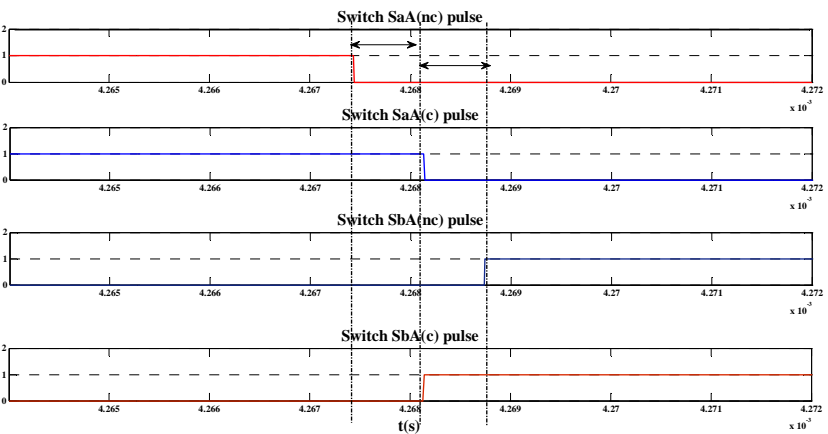

Fig.10 Switches pulses in four-step commutation has positive quantity output current $\mathrm{I}_{\mathrm{o}}$

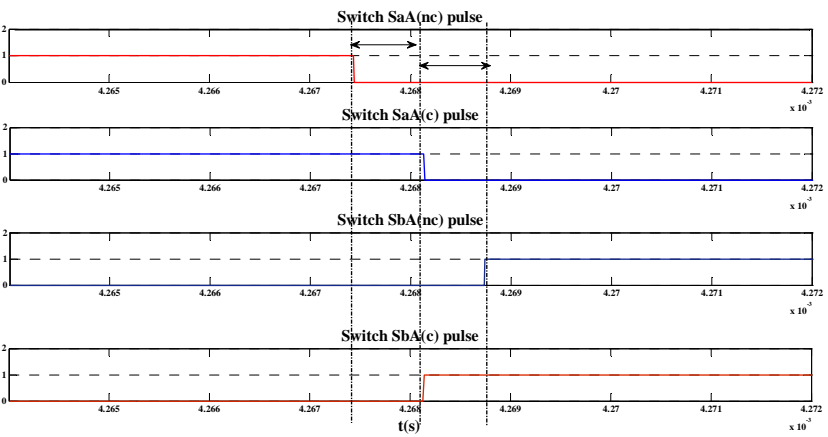

Fig.11 Switches pulses in four-step commutation has negative quantity output current $\mathrm{I}_{\mathrm{o}}$

\section{SIMULATION RESULTS}

Following simulation parameters are:

$V_{a}=220 \cos (100 \pi t), L_{s}$ and $C_{s}$ in the input filter frequency are $200 \mu \mathrm{H}, 30 \mu \mathrm{F}$. Switching frequency, $\mathrm{F}_{\mathrm{s}}$, is equal to $5 \mathrm{KHz}$.

\section{A. Convention matrix converter(CMC)}

Fig. 12(a) illustrates the voltages of each phase for matrix converter CMC with four-step commutation. The desired output currents are:

$V_{o 1}=100 \cos (100 \pi t), V_{o 2}=100 \cos \left(100 \pi t+\frac{\pi}{2}\right)$

The results of simulation for the case of considering the time of turning the switches on or off are the same as the case ignoring them, so these results are not reported here. Because turning the switches on and off are instaneously in simulation. 
Fig. 12(b) illustrates the harmonic spectrums of output voltages, where the maximum phase of first output voltage occurs in fundamental frequency of $98.99 \mathrm{v}$, with THD $=2.6565 \%$ and maximum phase of second output voltage occurs in fundamental frequency of $100.2 \mathrm{v}$, with $\mathrm{THD}=2.54 \%$.

Fig. 13(a) illustrates the input current of phase a for matrix converter CMC with four-step commutation, also Fig. 13(b) shows the harmonic spectrums of this current, where the THD of input currents of three phases are less than $8 \%$.

\section{B. Indirect matrix converter}

The input current of phase a is illustrated for matrix converter IMC with reduced switches in Fig.14(a). In Fig.14(b) the harmonic spectrums for input current of phase a is illustrated, in which the amount of THD (Total Harmonic Distortion) of that is 7.3274. As it is obvious in Fig.14(b), this current has only the 5th, 7th and 11th harmonics with significant amounts, while other harmonic distortions are negligible.

Fig. 15 is DC voltage link, and this de voltage is appropriate for inverter section.

Fig. 16(a) illustrates the voltages of each phase for matrix converter IMC. The desired output currents are:

$V_{o 1}=220 \cos (100 \pi t), V_{o 2}=220 \cos \left(100 \pi t+\frac{\pi}{2}\right)$

Fig. 16(b) illustrates the harmonic spectrums of output voltages, where the maximum phase of first output voltage occurs in fundamental frequency of $222 \mathrm{v}$, with THD $=5.9220 \%$ and maximum phase of second output voltage occurs in fundamental frequency of $221 \mathrm{v}$, with $\mathrm{THD}=5.9041 \%$. By filtering output voltages by the means of low-pass filters, the difference between output phase voltages has equaled to $90^{\circ}$ as shown in Fig. 16(c).
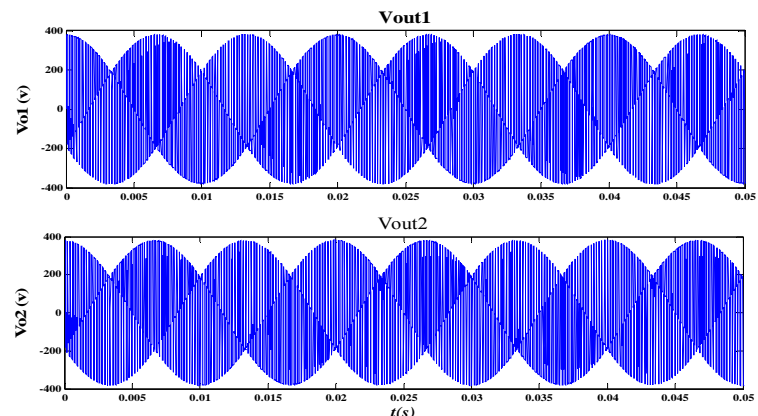

a)
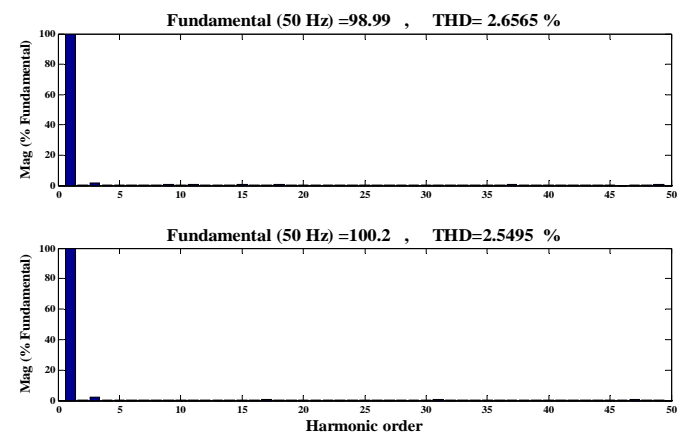

b)

Fig.12 Output voltages in phase for CMC matrix converter in four-step commutation

a) Waveforms b) Harmonic spectrum



a)

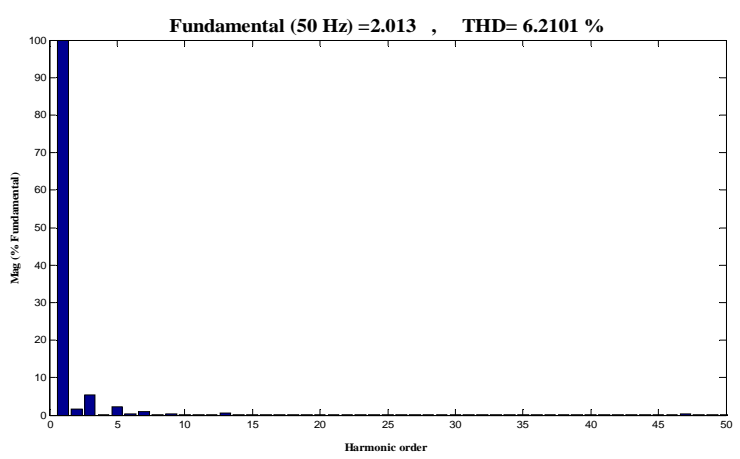

b)

Fig.13 Input currents for CMC matrix converter in four-step commutation a) Waveforms b) Harmonic spectrum

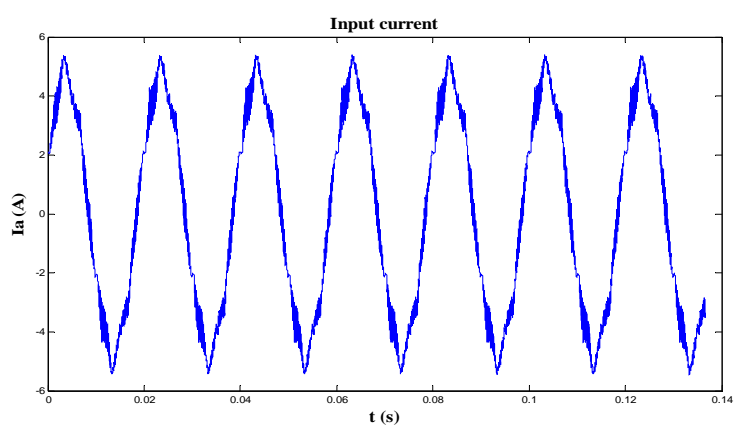

a)

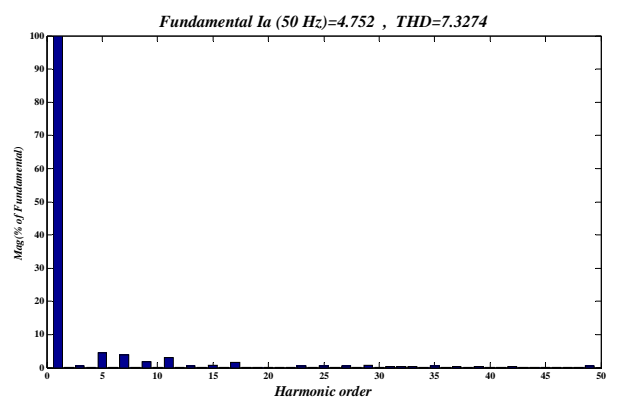

b)

Fig.14 Input current for IMC matrix converter with reduced switches

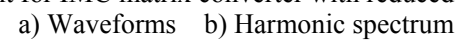




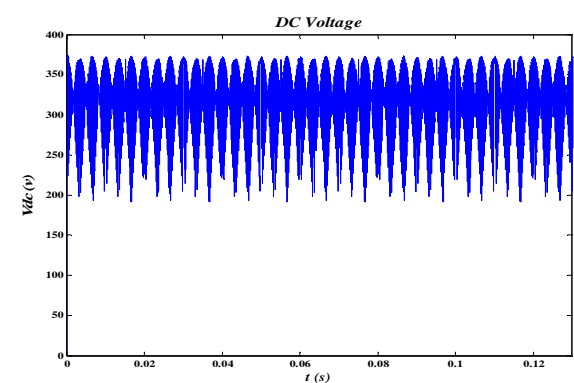

Fig.15 Voltage of DC link for IMC matrix converter with reduced switches


a)


b)

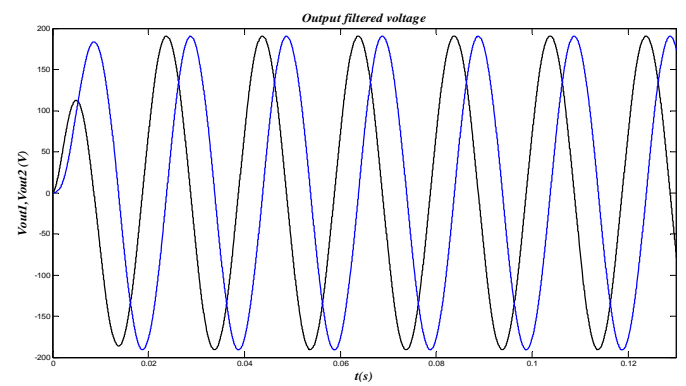

c)

Fig.16 Output Voltages for IMC matrix converter with reduced switches a) Waveforms b) Harmonic spectrum c) Filtered voltages

\section{CONCLUSION}

The circuit topologies and control schemes for two-phase matrix converter have been presented. The modulation schemes for the three-leg, two-phase ac-ac matrix converter have been developed based on SVM. In the proposed system on the Developed strategy, the matrix converter directly and with no dc link, generates two-phase sinusoidal waveforms. The proposed matrix converter provides sinusoidal output current/voltage waveforms with independently controlled magnitude and $90^{\circ}$ phase angle to two-phase loads. Simulation results prove that the algorithm work goog with low THD.

\section{REFERENCES}

[1] Alberto Alesina and Marco G. B. Venturini, "Solid-state conversion: A fourier analysis approach to generalized transformer synthesis," IEEE Transactions on Circuits and Systems, vol. CAS-28, No. 4, pp. 319 \{330, April 1981.

[2] P.Nielsen and F. Blaabjerg and J. K. Pedersen, "New Protection Issues of a Matrix Converter: Design Considerations for Adjustable-Speed Drive" in IEEE Trans. On Industry Applications, Vol. 35, No. 5, 1999, pp. 11501161

[3] L.Huber and D. Borojevic, "Space Vector Modulated Three-Phase to Three-Phase Matrix Converter with Input Power Factor Correction", IEEE Trans. On Industry Application, Vol. 31, No. 6, pp. 1234-1246, 1995

[4] M. Milanovic and B. Dobaj, "A Novel Unity Power Factor Correction Principle in Direct Ac to AC Matrix Converter", IEEE Power Electronics Specialists Conference, pp. 746- 752, 1998

[5] P.Ziogas, Y.Kang, V.Stefanovic,"Rectifire-inverter frequency changers with suppressed DC link components", In proceedings of IEEE IAS`1985, pp.1180-1189.

[6] Lixiang Wei, T.A.Lipo, Ho Chan, "Matrix Converter Topologies With Reduced Number of Switches" Power Electronics Specialists Conference, 2002. pesc 02. 2002 IEEE 33rd Annual, pp. 57- 63 vol.1, 2002

[7] Sangshin Kwak Member, IEEE, Hamid A. Toliyat Senior Member, IEEE "Direct AC/AC Converters with 2 Legs and 3 Legs for Two-Phase Systems" Power Electronics Specialists Conference, 2006. PESC '06. 37th IEEE pp, 1-5, 18-22 June 2006

[8] Hamid A. Toliyat "DSP-Based electromechanical motion control” (C) 2004 by CRC Press LLC, pp.320-321 